\title{
Arte, ciência e professorxs nO coração da loucura
}

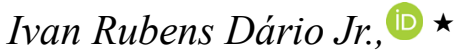 \\ Universidade Estadual Paulista, Rio Claro, SP, Brasil
}

\begin{abstract}
Resumo
O presente Relato de Experiência Profissional pretende investigar um encontro formativo integrando professores/as de Artes com professores/as de Ciências na rede municipal de São José dos Campos/SP. Foi utilizado o longa-metragem "Nise - o coração da loucura" como sustentação para debater e refletir sobre as práticas realizadas nas escolas e salas de aula. O objetivo foi registrar a experiência desse encontro de professores/as, apresentando algumas falas que denotam deslocamentos na maneira como professoras e professores enxergam a relação professor-estudante e as diversas possibilidades pedagógicas de intervenção. $O$ pensamento de Jorge Larrosa, Romualdo Dias, Gilles Deleuze e Nise da Silveira funciona como lente para nossa observação. Música e cinema como território comum para o movimento de pensamento do grupo e abertura de possíveis. Entre pincéis e picadores de gelo, a tentativa de um texto-fluxo permite perceber pontos de contatos entre hospital e escola; a vida entre forças de interdição e forças de expansão; estar em horário de trabalho coletivo na perspectiva do encontro e da experiência.
\end{abstract}

Palavras-chaves: arte; educação; encontro; experiência; loucura.

\section{Art, science and teachers in the heart of madness}

\begin{abstract}
The present Professional Experience Report intends to investigate a formative meeting integrating Arts teachers with Science teachers in the municipal network of São José dos Campos / SP that used the feature film Nise - the heart of madness as a support to debate and reflect on the practices carried out in schools and classrooms. It aims to record the experience of this meeting of teachers, presenting some speeches that present shifts in the way teachers and teachers see the teacher-student relationship and the various pedagogical possibilities of intervention. The thought of Jorge Larrosa, Romualdo Dias, Gilles Deleuze and Nise da Silveira works as a lens for our observation. Music and cinema as a common territory for the group's movement of thought and opening up possibilities. Between brushes and ice picks, the attempt of a flow text allows to perceive points of contact between hospital and school; Life between forces of interdiction and forces of expansion; Be in collective work hours in the perspective of the encounter and the experience.
\end{abstract}

Keywords: art; education; meeting; experience; craziness.

\section{Arte, ciencia y profesores en el corazón de la locura}

\begin{abstract}
Resumen
El presente Informe de Experiencia Profesional pretende investigar un encuentro formativo que integra a profesores de Artes con profesores de Ciencias en la red municipal de São José dos Campos / SP que utilizó el largometraje Nise - el corazón de la locura como soporte para debatir y reflexionar sobre las prácticas realizadas en escuelas y aulas. Tiene como objetivo registrar la experiencia de este encuentro de docentes, presentando algunos discursos que presentan cambios en la forma en que docentes $y$ docentes ven la relación docente-alumno y las diversas posibilidades pedagógicas de intervención. El pensamiento de Jorge Larrosa, Romualdo Dias, Gilles Deleuze y Nise da Silveira funciona como lente de nuestra observación. La música y el cine como territorio común para el movimiento de pensamiento del grupo y la apertura de posibilidades. Entre pinceles y picahielos, el intento de un texto fluído permite percibir puntos de contacto entre el hospital y la escuela; vida entre fuerzas de interdicción y fuerzas de expansión; estar en horas de trabajo colectivo en la perspectiva del encuentro y la experiencia.
\end{abstract}

Palabras clave: arte; educación; reunión; experiência; locura.

\section{Apresentação}

No período compreendido entre 2014 e 2016, a Secretaria Municipal de Educação de São José dos Campos - SP apresentou um programa de formação continuada para os/ as profissionais da rede municipal com o eixo Educação e Democracia. Esse tema articulava as grandes palestras na abertura dos anos letivos, cursos e oficinas durante o ano e os Horários de Trabalho Coletivo. Os HTCs eram concebidos na Secretaria Municipal de Educação por meio das professoras coordenadoras de área, que preparavam os

\footnotetext{
^Endereço para correspondência: Universidade Estadual Paulista, Campus de Rio Claro, Instituto de Biociências. Avenida 24-A, nº 1515, Bela Vista - Rio Claro, SP - Brasil. CEP 13506-900.E-mails: ivanrubens@hotmail.com.br Os dados completos do autor encontram-se ao final do artigo.
}

encontros formativos com o grupo de professores por área de conhecimento. Essa política de formação continuada também organizava ações envolvendo funcionários/as, comunidades escolares e estudantes.

Neste contexto mais amplo da política de formação continuada, acompanhamos os HTCs que integraram professores/as (ensino fundamental 1 e 2) de Artes com professores/as (ensino fundamental 2) de Ciências. Duas professoras coordenadoras de área organizaram, a partir da SME, os HTCs partindo do longa-metragem Nise - o coração da loucura (2015), utilizado como recurso didático e disparador do diálogo, da conversa e do pensamento. O presente Relato de Experiência Profissional tem o 
objetivo de registrar alguns aspectos desse encontro de professores/as de Artes e Ciências; registrar algumas falas que possam sugerir algum deslocamento de sentido.

\section{$O$ encontro}

$\mathrm{O}$ encontro aconteceu numa manhã de setembro de 2016. Cerca de 35 professoras/es de Arte e professores/ as de Ciências reunidos/as pelas respectivas professoras coordenadoras de área num encontro interdisciplinar. O disparador do encontro foi o longa-metragem brasileiro NISE - o coração da loucura (2015), ${ }^{1}$ dirigido por Roberto Berliner. $\mathrm{O}$ filme é baseado em um momento da vida da médica psiquiatra Nise da Silveira, pioneira da terapia ocupacional no Brasil. Ao sair da prisão na primeira metade da década de 1930, Nise retoma seus trabalhos no hospital psiquiátrico Pedro II, no bairro Engenho de Dentro, cidade do Rio de Janeiro, onde se recusa a empregar eletrochoque e lobotomia no tratamento de pacientes esquizofrênicos/as. Isolada pelos médicos conservadores, ela assume $o$ abandonado setor de Terapêutica Ocupacional, iniciando uma revolução de amor, arte e loucura. $\mathrm{O}$ filme funciona como recurso didático na medida em que produz um território comum para o grupo de professoras/ es e, a partir dos afetos produzidos no encontro, aponta o olhar para o cotidiano das escolas.

Durante uma palestra em São José dos Campos, o professor Jorge Larrosa chamou a atenção de professores/as para a etimologia da palavra "escola", do grego skolé: tempo livre. Falou da "experiência" como aquilo que nos atravessa. No Abecedário de Educação, Larrosa (2017) diz que o professor faz com que aula seja aula e, ao mesmo tempo, a aula constitui o professor como professor. Cabe ao professor selecionar, eleger conteúdos (textos, filmes, etc.), ordená-los de modo a constituir um percurso com seus alunos. Eleger bem é, para Larrosa, um ato de elegância. A elegância das duas professoras coordenadoras de área se materializou na exibição de uma obra de arte para aproximação e integração de duas áreas do conhecimento.

Feitas as apresentações iniciais, a sala de cinema do CEFE foi ganhando as cores do filme em seu deslocamento de tonalidades sombrias para as cores vivas e alegres. Destacamos abaixo um diálogo entre Mário Magalhães e Nise da Silveira.

Mário: "Tem muita coisa para fazer nesse país no lugar de ficar fazendo recreação, divertindo pacientes. Terapia ocupacional, sabe o que é isso, Nise? Você vai comprometer a sua carreira".

Nise: "Não estou ligando a mínima para a minha carreira, Mário. Até porque essa é a única alternativa para eu continuar no hospital".

Mario: "Ninguém dá a mínima para este setor. Ele é administrado por serventes".

Nise: "Olha, Mário, quem se preocupa muito com o que os outros dizem acaba deixando de viver. Eu sei o que é melhor para mim: eu quero é trabalhar!"

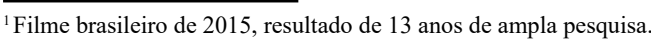

Mário muda de assunto: "Outro dia o Lord Byron 2 urinou no meu paletó".

E Nise: "Você não deveria falar isso, Mário. Nossos gatos são educadíssimos".

Nossos gatos são educadíssimos: interessante pensar no emprego da palavra educação em referência aos gatos ainda filhotes. Se ainda são filhotes, como são educadíssimos? Mas gatos não frequentam escolas! Como gatos podem ser educadíssimos, filhotes e não escolarizados? Seria um ser vivo já educadíssimo ao nascer? Nise vê na atitude do filhote demonstração de boa educação. $\mathrm{O}$ que seria uma educação que considera as necessidades do corpo? Aberturas para conversa...

A voz de Marina Mescheriakova ${ }^{3}$ interpretando Norma, Act I: Casta diva, de Vincenzo Bellini ${ }^{4}$ faz a transição desta cena de diálogo para uma cena de violência. Enquanto Nise e Mário dialogam sobre gatos e educação, no hospital a briga entre dois pacientes esquizofrênicos foi, por assim dizer, agenciada pelo enfermeiro Lima, que diz: "Vamos trabalhar...", como se soando um gongo para início da barbárie. Que concepção de trabalho está em Lima? Seria essa concepção de trabalho a mesma de Lima durante o filme? O enfermeiro Lima é um personagem marcador do deslocamento durante o filme. Este personagem vai se transformando com as transformações que acontecem no Hospital Pedro II a partir das experimentações no setor de terapêutica ocupacional. Com as transformações em Lima, teriam acontecido igualmente transformações em sua concepção de trabalho? Olhando para o personagem Lima em suas transformações, podemos pensar outros Limas. Haveria Limas apenas nos hospitais? Quanto de Lima trazemos em nós? É possível observar os deslocamentos em nossos alunos e alunas durante seus processos educacionais?

Bem, se concordamos que tais transformações aos empurrões, esbarramentos e solavancos que sentimos da vida nos transformam, nos modificam, nos produzem outros/as, como é possível pensar coisas fixas como grades nos processos educacionais e nas escolas? Com o filósofo Gilles Deleuze, convidamos os professores e professoras a pensar a aula como um movimento musical.

Uma aula é uma espécie de matéria em movimento. É por isso que é musical. [...] Uma aula é emoção, é tanto emoção quanto inteligência, sem emoção não há nada, não há interesse algum. Não é uma questão de entender e ouvir tudo, mas de acordar em tempo de captar o que lhe convém pessoalmente. É por isso que um público variado é muito importante. Sentimos o deslocamento do centro de interesse que pulam de um lado para o outro. Isso forma uma espécie de tecido esplêndido, uma espécie de textura (DELEUZE, 2018, p. 75).

O filme emociona os corpos docentes. A canção Todo Cambia com Mercedes Sosa (2013) também:

${ }^{2}$ Neste caso não se trata do poeta britânico (1788-1824), mas de um dos gatos do casal. Gatos que funcionam como marcação temporal: filhotes no início, aparecem em outras cenas sempre maiores.

${ }^{3}$ Marina Ivanovna Mescheriakowa é uma cantora de ópera russa (soprano).

${ }^{4}$ Vincenzo Salvatore Carmelo Francesco Bellini (1801-1835) foi um compositor italiano.

Fractal, Rev. Psicol., v. 33 - n. 2, p. 84-90, 2021 
Cambia lo superficial

Cambia también lo profundo

Cambia el modo de pensar

Cambia todo en este mundo

Cambia el clima con los años

Cambia el pastor su rebaño

$Y$ así como todo cambia

Que yo cambie no es extraño

Cambia el mas fino brillante

De mano en mano su brillo

Cambia el nido el pajarillo

Cambia el sentir un amante

Cambia el rumbo el caminhante

Aúnque esto le cause daño

Y así como todo cambia

Que yo cambie no es extraño

Cambia todo cambia

Cambia todo cambia

Cambia todo cambia

Cambia todo cambia

No pensamento de Jorge Larrosa, "experiência” é aquilo que nos atravessa a ponto de produzir alguma transformação, alguma mudança. Com o professor Romualdo Dias (2015, p. 16), entendemos por deslocamento "tudo aquilo que se refere a uma concepção de processo, de movimento [...] no sentido de romper com os mecanismos de tutela, [...] como aventura, na configuração de um lugar e um modo de habitar o trabalho e compreendê-lo".

O filme começa com cenas escuras, com os pacientes do hospital psiquiátrico tratados como animais. Uma professora evitou as primeiras cenas: "É muito violento", disse. Devagar o filme vai mudando. O setor de Terapêutica Ocupacional vai se transformando em ateliê de pintura e, a cada movimento, as janelas trancadas são abertas, trazendo ares e luzes; as telas ganham cores, e as cenas ganham beleza e emoção. Cinema é imagem em movimento e, no movimento dessas imagens, o diretor é muito feliz em produzir uma certa pedagogia da beleza: o filme conduz o/a espectador/a a uma experiência de beleza e humanização. ${ }^{5} \mathrm{Na}$ sala de cinema ouvimos respirações, risos sutis e até risadas. Também ouvimos suspiros e choros. Ao final, luzes acesas, olhos vermelhos, falas embargadas e muita emoção. A professora coordenadora da área de ciência inicia o debate.

As primeiras falas de professores/as trazem o tema da pessoa com deficiência. A deficiência na escola tem no laudo médico uma espécie de verdade absoluta sobre uma criança. O outro lado disso é rotulação pesada para uma criança carregar. Contudo uma certa dificul-

${ }^{5}$ Pensamos aqui como Paulo Freire (1969) em Papel da educação na humanização. dade com a linguagem escrita, por exemplo, não é necessariamente captada por um laudo médico, tampouco pela verdade representada no diagnóstico ou na doença. Verdade? Possibilidade de experimentação de outras linguagens, por exemplo? Uma professora conta o caso da criança cuja comunicação por desenhos flui muito bem, inclusive expressando, segundo ela, um raciocínio lógico. Tal raciocínio se expressa em forma de desenho, mas não se expressa (pelo menos ainda) na leitura e escrita.

Um segundo movimento nas falas traz o exercício de juntar as áreas da ciência e da arte. As falas sugeriram que o humano não está pronto, ele se produz. Não se trata de uma técnica porque a técnica não dá conta da vida. Ligar arte e ciência é abrir perspectivas para pensar ambas. A pesquisa, como habitualmente concebida e realizada no Brasil em nosso tempo, é, segundo as falas do grupo, positivista e quantitativa. Para esses professores, esta metodologia científica dá conta das ciências exatas, mas não dá conta das humanidades. Na realidade das salas de aula, convivemos com alunos e alunas que aprendem, mas e os que não aprendem? Nós, professores/as, conseguimos utilizar instrumentos para incluí-los/ as no aprendizado? O que fazer? Talvez o caminho seja o de experimentar outras possibilidades, outras linguagens. No filme, quando a estagiária Marta (Pires Ferreira) chega ao hospital e é apresentada por Almir (Mavignier), Nise dá as boas-vindas oferecendo a ela dois livros.

Nise: "Tome, leia de cabo a rabo e depois volte. Mas enquanto isso sente ai".

Nise da Silveira não está sozinha, porque o conhecimento produzido por outros que já se dedicaram a tais temas-pesquisas-estudos-experimentações dá sustentação ao seu movimento de construção de conhecimento com os esquizofrênicos no Engenho de Dentro. Ela se apoia na Teoria.

Lembramos, durante este nosso encontro de estudos, aos professores de artes e de ciências, do tempo em que o cantor e compositor baiano Gilberto Gil foi atravessado pela física quântica, o que resultou no álbum Quanta. No encarte deste disco, um detalhe curioso: está reproduzida uma carta de Cesar Lattes ${ }^{6}$ destinada a Gil. Na canção "Quanta", o ex-ministro de Estado da Cultura diz assim:

\section{Quanta do latim}

Plural de quantum

Quando quase não há

Quantidade que se medir

Qualidade que se expressar

Fragmento infinitésimo

Quase que apenas mental

Quantum granulado no mel

Quantum ondulado no sal

Mel de urânio, sal de rádio

${ }^{6}$ Césare Mansueto Giulio Lattes (Curitiba, 1924 - Campinas, 2005), físico brasileiro, codescobridor do méson pi, descoberta que levou o Prêmio Nobel de Física de 1950, concedido a Cecil Frank Powell. 
Qualquer coisa quase ideal

Cântico dos cânticos

Quântico dos quânticos

Canto de louvor

De amor ao vento

Vento, arte do ar

Balançando o corpo da flor

Levando o veleiro pro mar

Vento de calor

De pensamento em chamas

Inspiração

Arte de criar o saber

Arte, descoberta, invenção

Theoría em grego quer dizer

O ser em contemplação

Cântico dos cânticos

Quântico dos quânticos

Sei que a arte é irmã da ciência

Ambas filhas de um deus fugaz

Que faz num momento e no mesmo momento desfaz

Esse vago deus por trás do mundo

Por detrás do detrás

Cântico dos cânticos

Quântico dos quânticos

(GIL, 2003)

Um dos presentes afirma que o professor deve recorrer às teorias para se embasar, que o conhecimento, a ciência, as teorias são o apoio, a base que sustenta a ação de dar aula. Contudo a ciência sozinha não dá conta da vida. Arte e Ciência são grandezas que, caminhando juntas, trilham interessantes percursos. Ou, nas palavras de Gil (2003, p. 430): "Theoría em grego quer dizer o ser em contemplação", ou ainda, "a arte é irmã da ciência, ambas filhas de um deus fugaz, que faz num momento e no mesmo momento desfaz".

Voltemos ao filme. Apesar da precariedade, Nise conseguiu fazer muita coisa. O filme mostra que alguma ação sempre é possível. Ela construiu um ambiente acolhedor para que os esquizofrênicos pudessem viver e conviver mesmo na mais absoluta miséria e pobreza. E nesse ambiente acolhedor, onde os gestos foram gradativamente ganhando delicadezas, o amor começou a brilhar. E não apenas o amor (e isso não é pouco) mas também o próprio filme vai ganhando luz e cores. O cuidado da direção faz com que as cores das telas ao toque dos pincéis e da criação artística não se limitem às telas, mas brilhem em todo o ambiente, iluminando e colorindo o hospital psiquiátrico. Cores das telas para a telona. Os contornos da vida balançam, tremem, se desfazem, e ao mesmo tempo a vida ganha novos contornos, a vida se ilumina como o ambiente do filme, a vida vai ganhando as cores das telas. A vida vai se transformando numa vida outra.

"Como vocês se sentiram? O que do filme afetou vocês?"

Disse um professor, com a voz muito embargada: "Nunca mais veremos um aluno especial da mesma forma. Este filme mudou nosso olhar para as crianças especiais na escola". Este professor, da área de ciências, está muito envolvido com um projeto de horta numa escola da periferia da cidade. Uma grande horta que havia na escola, paixão de um ex-professor, foi assumida por este jovem professor e um grupo de alunos. Há, portanto, da parte deste professor, um contato frequente com a terra, com sementes, germinação, com a vida. No filme, o paciente Carlos Pertuis mostra sua paixão por sementes: "Semente não é lixo. Semente é vida. Semente que nasce, que dá vida e dá outra semente". Logo Carlinhos que "via Deus nos raios de Sol. E queria que todo mundo visse também", pintava mandalas douradas, que, para Nise da Silveira, representam, em algumas culturas, a presença de Deus. E o professor-agricultor-cuidador, sim, porque ele cultiva sementes, cuida da terra, cuida da vida e, provavelmente, cuida de alunos e alunas na escola, reconhece que Nise acreditava na vida, acreditava no que fazia, ela era movida pela força das suas convicções. E, dessa maneira, o professor-agricultor-cuidador traz para nosso debate o tema do amor. Uma professora lembra da palestra do professor Leonardo Boff (realizada na cidade de São José dos Campos no início de 2014) e acrescenta o tema do cuidado. Para ela, Boff abriu perspectivas para pensar o cuidado com a terra, a Pacha Mama, ${ }^{7}$ e nos permite pensar numa terragogia.

Para uma professora de ciências presente, "a educação é sempre tida como um patinho feio. Aquela área meio desacreditada, considerada menor". Ela provoca um debate sobre metodologia: "Qual a metodologia de Nise?" Já no início do filme, Nise diz ao diretor do hospital que não utilizaria lobotomia e eletrochoque. Portanto, ela parece saber o que não faria. Porque já está num movimento de pesquisa na busca de um outro caminho. Uma espécie de convicção invertida se consideradas as opções dos médicos de então, todos homens no filme, cujas técnicas consideradas avançadas para a época e validadas pela comunidade psiquiátrica são inadmissíveis para Nise da Silveira. Nise não tem uma fórmula pronta, ela vai tentando, vai experimentando. Uma cena é emblemática: ela convida os esquizofrênicos para conversar, sugere uma roda de conversa, mas percebe que essa escolha tem problemas. Neste movimento, ela vai produzindo um método de trabalho que considera o grupo de pacientes e cada paciente. Sua convicção, respeito e cuidado com cada paciente vai contagiando devagar as pessoas no hospital, ela estabelece parcerias. Sua experiência é empírica e funciona.

Eis que uma fala chega como um soco do paciente Lúcio Noeman, aquele da briga que inicia o filme. Uma professora destaca o paciente como "crônico incurável".

${ }^{7}$ Pacha Mama ou Pachamama (do quíchua Pacha, "universo", "mundo", "tempo", "lugar”, e Mama, "mãe", "Mãe Terra"). 
Assim era considerado Emygdio de Barros, um crônico incurável. Logo ele que, considerado pelo crítico de arte Mário Pedrosa "um dos maiores pintores do Brasil", se afirma operário. Sim, porque trazia viva na memória sua experiência de torneiro mecânico na marinha do Brasil. Logo ele que, na sua despedida do hospital, afirma: "Enquanto eu continuar aqui no engenho de dentro eu vou continuar pintando". O Hospital Psiquiátrico Pedro II fica no Engenho de Dentro, bairro da zona Norte carioca. Mas Emygdio está se referindo ao engenho de dentro como profundeza de si, uma subjetividade engenhosa. Numa busca rápida nos dicionários da língua portuguesa encontramos definições para "engenho": capacidade de criar, produzir com arte, criatividade, inventividade. Ou ainda: uma capacidade posta em prática; criação, produção, realização.

Levando para a realidade da escola, a professora lembra que todos os professores já conviveram com aquele "menino impossível", palavras dela. Aquele menino difícil, que exige ainda mais da professora. E a gente aceita essa verdade. Aceita, sequer contesta. A gente aceita que o menino é impossível, que outros professores já chegaram a ponto de desistir do menino. Quantos meninos assim, rotulados como "impossíveis", incapazes, improdutivos são, de alguma maneira, os "crônicos incuráveis"? Se Nise desistisse de Emygdio, se Almir não insistisse com Emygdio, qual seria o destino dele? A obra de Emygdio existiria? A exemplo de Nise, nós, professores, não podemos desistir dos alunos. A aposta da doutora Nise é o amor.

Outra professora afirma conhecer o hospital Pedro II. O filme apresenta uma história ocorrida na década de 1940, já a produção aconteceu na primeira metade da década de 2010. Foi rodado no mesmo hospital Pedro II, e os atuais "pacientes" atuaram no filme. Esta professora conta que trabalhou lá. Não foi contemporânea de Nise, mas para ela o pensamento de Nise da Silveira ainda é muito presente na psiquiatria atual. Uma médica que soube trabalhar a partir da arte. Na verdade, pensamos que Nise valorizou mesmo foi a vida e o trabalho. Não um trabalho alienado que atende meramente aos interesses do mercado e da reprodução do capital. Mas um trabalho no sentido da produção de uma obra que, ao esculpir a argila, esculpe a si mesmo. $\mathrm{O}$ trabalho como escultura de si. Lúcio Noeman (mais um personagem marcador do deslocamento) esculpe guerreiros na argila e, ao mesmo tempo, vai se produzindo um sujeito outro, vai produzindo sentidos para sua vida. Aqui estamos pensando com o Romualdo Dias (2015), a Educação compreendida como a mútua implicação de produção de subjetividade e processos educacionais.

E, de alguma forma, o próprio trabalho de Nise também está em jogo durante o filme. $\mathrm{O}$ diretor faz questão de destacar este ponto quando Mário Pedrosa, o crítico de arte, afirma que aquela experiência artística com os esquizofrênicos/as não pode se restringir a uma investigação científica porque ele é arte. Diante da tela, Almir Marvigner, artista plástico e assistente de Nise no Ateliê, explica para Mário Pedrosa as técnicas de pintura de Emygdio de Barros: "Emygdio sempre começa com essas pinceladas bem curtas e, a partir delas, ele vai estruturando o resto da pintura. São os piques essas pinceladinhas". E Pedrosa comenta, como se falando consigo mesmo: "Nós passamos anos estudando história da arte, métodos, os pintores do mundo todo para um dia eu me deparar com isso no meio de um hospital psiquiátrico". Ele toca em Emygdio e diz: "Emygdio, você é um dos maiores pintores brasileiros". Ao que Emygdio responde: "Eu não sou pintor. Eu sou um operário. Mas enquanto eu estiver por aqui eu sigo pintando".

"Aqui" de Emygdio é onde? A cena prossegue com Pedrosa se dirigindo a Nise:

Isso não é só uma investigação científica. É também artística, é política também. Eu conversei com muitas pessoas sobre a revolução que você está fazendo aqui no hospital. Nós temos que sair destes muros, levar este trabalho para fora. As pessoas merecem ver isso. Nise, você está isolada à mercê dos seus colegas reacionários. Nise, não é a ciência que vai garantir o seu trabalho. É a arte.

Interessante pensar esse movimento do filme. O tema do trabalho foi muito bem captado pelo diretor. Os conhecedores da obra da médica, do trabalho de Nise da Silveira, seus contemporâneos que o assessoraram na elaboração do roteiro, captaram muito bem este tema e colocaram-no na obra de ficção. Ela fala e escreve sobre o trabalho. Trata-se de um tema recorrente. No documentário-entrevista intitulado Posfácio: imagens do inconsciente, Nise da Silveira (1986) afirma:

$\mathrm{O}$ que eu queria, o que me fascinava era o que acontecia dentro da cuca do esquizofrênico debaixo daquele aspecto miserável e atoleimado, diferenciado, alienado, era de repente um gesto de mão de Rafael que estava doente desde os dezesseis anos, que urinava no chão e esfregava as mãos na urina. Mas ele fazia de repente um gesto e eu digo: tem que haver alguma coisa. Não acho imutável, não. É uma questão de aceitar a dignidade do trabalho seja ele qual for. Politicamente, o âmago é aceitar a dignidade do trabalho. E o trabalho não é uma coisa servil. Ele exprime a alma da pessoa.

Queremos ressaltar dois aspectos do pensamento acima. $\mathrm{O}$ primeiro refere-se à curiosidade da pesquisadora com aquilo que acontece "dentro da cuca" - que fluxos, que elaborações, que emoções, que movimentos acontecem dentro da cuca? - e seu olhar atento aos detalhes do comportamento dos esquizofrênicos: "um gesto de Rafael", apenas um gesto é capaz de revelar mundos. Este ponto nos leva a pensar numa espécie de formação continuada situada no acompanhamento dos processos educacionais, no autodidatismo e na cultura de estudo. O segundo aspecto refere-se à dimensão política do trabalho. O trabalho como expressão da alma humana. Um trabalho na perspectiva do oikós, do grego, que significa "casa, lar, domicílio, meio ambiente", na direção de uma economia do sujeito. Um trabalho cuja obra revela um processo investigativo, um mergulho no mundo interior que vai se revelando aos poucos. O paciente Fernando Diniz sabe bem disso. Em seu mergulho em si mesmo, em seu processo de elaboração dos traumas e suas dores do viver, os horizontes vão se ampliando: "Da janela aberta dá para ver a paisagem", diz Fernando. Compreendemos a janela como o lugar de passagem, aquele espaço de 
fronteira entre dentro e fora. $\mathrm{O}$ interior do ateliê de pintura e o pátio do hospital. Os dramas e traumas do interior de Fernando e todo o universo de possibilidade da natureza, do mundo povoado por outros seres. Mas essa ligação exige abertura. E Fernando vai elaborando, vai se esculpindo no sentido de conseguir se abrir para a alteridade, de se abrir para o mundo, de se permitir experimentar uma outra vida mais interessante que sua vida anterior.

Um professor de ciências chama a atenção para a ideia de investigação no sentido de perceber as biografias. Que na escola é possível descobrir as histórias de vida de alunos e alunas, em particular dos alunos que, nas suas palavras, "dão mais trabalho". Que a partir dos fragmentos das histórias de vida é possível compreender seu comportamento, e isso ajuda a inventar novos jeitos de trabalhar com eles.

A professora coordenadora da área de Artes fala da importância da arte na educação. Ela considera os humanos seres de cultura, e afirma: "A arte torna nossa vida mais saudável". Interessante pensar: seria óbvio antes de percebido? Porque o óbvio é, de fato, óbvio só depois de descoberto. É como se o óbvio estivesse diante de nossos olhos, ali, se exibindo, dançando, sambando sem ser percebido. Não era percebido visto que estava (por assim dizer) coberto. A partir do momento em que foi des-coberto torna-se obviedade. O óbvio é óbvio quando descoberto! Uma descoberta na perspectiva da brincadeira, aqui compreendida como uma infância. Porque, como disse a coordenadora, o lúdico, a brincadeira, a magia, a fabulação independe da idade. Ela nos alerta para a dimensão afetiva da brincadeira na produção da humanidade.

Um professor de cabelos brancos, voz forte e doce, toma o microfone. Ele torna óbvio um detalhe interessante do filme. O filme se inicia com Nise da Silveira batendo à porta do Hospital. Batendo. Esmurrando uma porta quase intransponível. O início do filme tem Nise tentando entrar numa instituição (hospital) quase impenetrável. E a história se desenrola entre fechamentos e aberturas, entre portas que fecham e abrem, entre janelas fechadas que se abrem. Entre forças de fechamentos, interdições, proibições, normas, regras e forças de aberturas, de invenção, de criação de novos mundos, caminhos novos, possibilidades outras. E o professor pergunta: "Por que não pode ser? Não pode mesmo? Por que?" Ele acrescenta que tem muita regra consolidada nas instituições, que são aceitas mas que perdem o sentido original com o tempo. E, quando colocadas em dúvida, alguém reclama. É um pouco como a história da roupa nova do rei. Até que um menino diz: o rei está nu. As regras na escola precisam ser discutidas permanentemente. Para não virarem letra morta, seus sentidos devem ser permanentemente vistos e revistos. Porque todos nós temos nossas sanidades e nossas loucuras. O que é normal? O que é normalidade? Usando uma imagem forte do filme, quantos picadores de gelo cada um de nós carrega diariamente? Quando fazemos uso deles? Mas nós também carregamos pincéis diariamente. Porque viver é equilibrar esses

Fractal, Rev. Psicol., v. 33 - n. 2, p. 84-90, 2021 polos, estar atento a eles todos, repetir até ficar diferente. Até superar esse maniqueísmo para uma forma de vida outra, melhor, mais humana.

E o professor acrescenta: "As rasuras nos diários de classe, por exemplo: picadores de gelo. Tem assunto que é levado ao ponto da tortura. E até parece que isso é tão importante assim, apesar de ser a prática em algumas escolas", ele completa.

Outro professor artista lembra que a alagoana Nise da Silveira é sua conterrânea. Mulher, nordestina, do menor Estado do Nordeste. Isso pode parecer um detalhe, mas não é. Trata-se de um Estado tido como inexpressivo. Além disso, há a questão da prisão num momento difícil e conturbado da história política do Brasil. E ainda os anos de exílio e toda a vida de Nise, todo acúmulo, suas experimentações. Tudo isso foi tornando aquele corpo mais forte, mais musculoso, com maiores condições de enfrentar adversidades sem se entregar. Uma mulher forte e convicta de seu caminho, que não baixava a cabeça e seguia em frente.

Já no momento das despedidas, o professor que tentou falar logo no início dos trabalhos (olha o trabalho ai), superada a emoção que embargava sua fala, cumprimentou de público a iniciativa de juntar professores de arte e ciências. É como, nas palavras dele, misturar café com leite. Misturar ciência e arte no sentido de nos dar vigor para a caminhada.

\section{Conclusão}

Buscamos construir um texto-fluxo, um texto feito no momento dos afetos, entre sensações provocadas por uma obra cinematográfica e reflexões sobre práticas diárias nas escolas. "Os hospitais são diferentes das escolas?", é a pergunta que ecoa. O que existe em comum nesses espaços é a vida pulsando entre forças de expansão e interdição, a produção do humano que se forma e se transforma a cada encontro, a cada ação. Registrar o movimento do pensamento sem enclausurá-lo, tentando não coisificá-lo é uma tarefa complexa. Exige desconstruir em nós mesmos as capturas e interdições do movimento.

As professoras e professores em HTCs experimentaram conosco essa ideia de livre pensar, utilizando os personagens do filme como espelho. Entre ações e pensamentos orientados por picadores de gelo ou pincéis, descobrimos que, para cada vida, existe ou pode haver uma pedagogia.

Com o pensamento do filósofo francês Gilles Deleuze (2014, p. 58), finalizamos com novas aberturas ético-estético-políticas:

Há vidas em que as dificuldades tocam o prodígio; são as vidas dos pensadores. E é preciso ouvir aquilo que nos contam a seu respeito, porque descobrimos aí as possibilidades de vida cuja simples narração já nos dá alegria e força e lança uma luz sobre a vida dos seus sucessores. Há aí tanta invenção, reflexão, audácia, desespero e esperança como nas viagens dos grandes navegadores; e, para falar a verdade, são também viagens de exploração nos domínios mais recuados e mais perigosos da vida. O que estas vidas têm de surpreendentes é que dois instintos inimigos, que puxam em sentidos 
opostos, parecem ser obrigados aí a caminhar sob o mesmo jugo; o instinto que tende para o conhecimento é constrangido, sem parar, a abandonar o chão em que o homem tem o costume de viver e a lançar-se no incerto e o instinto que quer a vida vê-se forçado a procurar, sem parar, às apalpadelas, um novo lugar onde se estabelecer [...] (grifos do autor).

Utilizar uma obra de arte, no nosso caso um filme e algumas canções, pode oferecer um chão comum para o trânsito do pensamento e, neste exercício, nesta viagem, exercitar o pensamento. Isso nos permitiu:

1. Experimentar com um grupo de professores uma maneira outra de estar em Horário de Trabalho Coletivo, aproximando 'áreas' diferentes e partilhando afetos e pensamentos; um HTC na perspectiva do encontro e da experiência;

2. Perceber duas forças tensionando em sentidos opostos. Uma que convida a alçar outras dimensões do pensamento e da vida, que convida a abandonar o chão onde se costuma viver e a lançar-se na incerteza, na tensão permanente com a outra força que opera no sentido contrário, que procura uma acomodação. Entre forças (movimentos) e formas (molduras), o traço do pintor e o limite do quadro.

\section{Informações sobre o autor:}

Ivan Rubens Dário Jr.

(iD) https://orcid.org/0000-0003-2719-5074

(9) http://lattes.cnpq.br/3071304925057880

Doutorando e mestre em Educação pela UNESP - Rio Claro (2016). Graduado em Geografia pela Universidade Estadual Paulista Júlio de Mesquita Filho (1999) (licenciatura e bacharelado). Tem atuação no serviço público com ênfase no trabalho com políticas de participação popular em governos municipais, sociedade civil e comunidades. Possui experiência em formação (e coordenação) de grupos de trabalho com ênfase nos processos de educação popular e processos de subjetivação. É articulista de jornais com circulação local e regional. É pesquisador vinculado ao Laboratório de Estudos em Políticas Públicas.

\section{Como citar este artigo:}

\section{ABNT}

DÁRIO JR., Ivan Rubens. Arte, ciência e professorxs nO coração da loucura. Fractal: Revista de Psicologia, Niterói, v. 33, n. 2, p. 84-90, maio/ago. 2021. https://doi.org/10.22409/1984-0292/ v33i2/5761

\section{APA}

Dário Jr., I. R. (2021, Maio/Agosto). Arte, ciência e professorxs nO coração da loucura. Fractal: Revista de Psicologia, 33(2), 84-90. doi: https://doi.org/10.22409/1984-0292/v33i2/5761

\section{Copyright:}

Copyright $(C 2021$ Dário Jr., I. R. Este é um artigo em acesso aberto distribuído nos termos da Licença Creative Commons Atribuição que permite o uso irrestrito, a distribuição e reprodução em qualquer meio desde que o artigo original seja devidamente citado.

Copyright (C) 2021 Dário Jr., I. R. This is an Open Access article distributed under the terms of the Creative Commons Attribution License, which permits unrestricted use, distribution, and reproduction in any medium, provided the original article is properly cited.

\section{Referências}

ABECEDÁRIO de Educação com Jorge Larrosa Bondía (por Adriana Fresquet). CINEAD LECAV. Youtube. 10 jul. 2017. 1h10min26s. Disponível em: https://www.youtube.com/ watch?app=desktop\&v=5FtY1psRoS4. Acesso em: 7 maio 2021.

DELEUZE, Gilles. Nietzsche. Tradução de Alberto Campos. Lisboa: Edições 70, 2014.

DELEUZE, Gilles. O ABECEDÁRIO de Gilles Deleuze. Clinicand, 13 jun. 2018. Entrevista concedida a Claire Parnet. Disponível em: http://clinicand.com/wp-content/ uploads/2021/02/Gilles_Deleuze_Claire_Parnet_Abeced_riozlib.org_pdf. Acesso: 4 jun. 2021.

DIAS, Romualdo. Educação de jovens e adultos: novas perspectivas! Curitiba, PR: Appris, 2015.

FREIRE, Paulo. Papel da educação na humanização. Revista Paz e Terra, São Paulo, n. 9, p. 123-132, out. 1969.

GIL, Gilberto. Todas as letras. Organização: Carlos Rennó. ed. ampl. e coment. São Paulo: Companhia das Letras, 2003.

NISE: O Coração da Loucura. Direção: Roberto Berliner. Produção: Rodrigo Letier e Lorena Bondarovsky. Intérpretes: Glória Pires; Simone Mazzer; Julio Adrião; Cláudio Jaborandy; Fabrício Boliveira; Roney Villela; Flávio Bauraqui; Bernardo Marinho; Roberta Rodrigues; Augusto Madeira; Zé Carlos Machado e outros. Roteiro: Roberto Berliner, Flávia Castro, Maurício Lissovski, Chris Alcazar, Maria Camargo, Patrícia Andrade, Leonardo Rocha. São Paulo: Imagem Filmes Produtora Ltda - Epp; W Mix Distribuidora de Filmes, 2015. (109 $\mathrm{min}$ ), color.

SILVEIRA, Nise da. Posfácio: imagens do inconsciente. Youtube, 15; 19 abr. 1986. 80min28s. Entrevista concedida a Leon Hirszman. Disponível em: https://www.youtube.com/ watch?app=desktop\&v=EDg0zjMe4nA. Acesso em: 7 maio 2021.

SOSA, Mercedes. Todo Cambia. Edição e sincronização: Matías Jiménez. Youtube, 14 jun. 2013.4min47s. Disponível em: https:// www.youtube.com/watch?app=desktop \&v=0khKL3tTOTs. Acesso em: 19 out. 2016. 